Article

\title{
Absence of Association between Previous Mycoplasma pneumoniae Infection and Subsequent Myasthenia Gravis: A Nationwide Population-Based Matched Cohort Study
}

\author{
Kuan Chen ${ }^{1}$, James Cheng-Chung Wei ${ }^{2,3,4, * \mathbb{C}}$, Hei-Tung Yip ${ }^{5,6,7} \mathbb{D}$, Mei-Chia Chou ${ }^{8,9, *}$ and Renin Chang ${ }^{1, * \mathbb{C}}$ \\ 1 Department of Emergency Medicine, Kaohsiung Veterans General Hospital, Kaohsiung 813414, Taiwan; \\ gauurgr1016@gmail.com \\ 2 Division of Allergy, Immunology and Rheumatology, Chung Shan Medical University Hospital, \\ Taichung 40201, Taiwan \\ 3 Institute of Medicine, Chung Shan Medical University, Taichung 40201, Taiwan \\ 4 Graduate Institute of Integrated Medicine, China Medical University, Taichung 40402, Taiwan \\ 5 Department of Management Office for Health Data, China Medical University Hospital, \\ Taichung 40402, Taiwan; fionyip0i0@gmail.com \\ 6 College of Medicine, China Medical University, Taichung 406040, Taiwan \\ 7 Institute of Public Health (Biostatistics), National Yangming University, Taipei 11221, Taiwan \\ 8 Department of Recreation and Sports Management, Tajen University, Pingtung County 90741, Taiwan \\ 9 Department of Physical Medicine and Rehabilitation, Kaohsiung Veterans General Hospital, Pingtung Branch, \\ Pingtung County 91245, Taiwan \\ check for \\ updates \\ Citation: Chen, K.; Wei, J.C.-C.; Yip, \\ * Correspondence: wei322@gmail.com (J.C.-C.W.); meeichia@gmail.com (M.-C.C.); \\ rhapsody1881@gmail.com (R.C.); Tel.: +886-8-770-4115 (M.-C.C.); +886-7-342-2121 (R.C.); \\ Fax: +886-7-342-2288 (R.C.)
} H.-T.; Chou, M.-C.; Chang, R. Absence of Association between Previous Mycoplasma pneumoniae Infection and Subsequent Myasthenia Gravis: A Nationwide

Population-Based Matched Cohort Study. Int. J. Environ. Res. Public Health 2021, 18, 7677. https:// doi.org/10.3390/ijerph18147677

Academic Editors: Chien-Lung Chan and Chi-Chang Chang

Received: 22 April 2021

Accepted: 14 July 2021

Published: 19 July 2021

Publisher's Note: MDPI stays neutral with regard to jurisdictional claims in published maps and institutional affiliations.

Copyright: () 2021 by the authors. Licensee MDPI, Basel, Switzerland. This article is an open access article distributed under the terms and conditions of the Creative Commons Attribution (CC BY) license (https:// creativecommons.org/licenses/by/ $4.0 /)$.

\begin{abstract}
Mycoplasma pneumoniae (M. pneumoniae) is not only one of the most common pathogenic bacteria for respiratory infection but also a trigger for many autoimmune diseases. Its infection process shared many similarities with the pathogenesis of myasthenia gravis (MG) at cellular and cytokine levels. Recent case reports demonstrated patients present with MG after M. pneumoniae infection. However, no epidemiological studies ever looked into the association between the two. Our study aimed to investigate the relationship between $M$. pneumoniae infection and subsequent development of MG. In this population-based retrospective cohort study, the risk of MG was analyzed in patients who were newly diagnosed with M. pneumoniae infection between 2000 and 2013. A total of 2428 M. pneumoniae patients were included and matched with the non-M. pneumoniae control cohort at a 1:4 ratio by age, sex, and index date. Cox proportional hazards regression analysis was applied to analyze the risk of MG development after adjusting for sex, age, and comorbidities, with hazard ratios and $95 \%$ confidence intervals. The incidence rates of MG in the non-M. pneumoniae and M. pneumoniae cohorts were 0.96 and 1.97 per 10,000 person-years, respectively. Another case-control study of patients with MG $(n=515)$ was conducted to analyze the impact of M. pneumoniae on MG occurrence as a sensitivity analysis. The analysis yielded consistent absence of a link between M. pneumoniae and MG. Although previous studies have reported that M. pneumoniae infection and MG may share associated immunologic pathways, we found no statistical significance between M. pneumoniae infection and subsequent development of MG in this study.
\end{abstract}

Keywords: Mycoplasma pneumoniae infection; myasthenia gravis; population-based; association

\section{Introduction}

The incidence of autoimmune diseases has been reported to be increasing worldwide. However, the triggers of most autoimmune diseases remain unclear. Among autoimmune diseases, myasthenia gravis (MG) is the most common neuromuscular junction disorder. The hallmark of this disorder is a fluctuating degree and variable combination of weakness in several muscle groups, such as ocular, bulbar, limb, and respiratory muscles. MG is 
a relatively uncommon disorder, with an annual incidence of approximately 7-23 new cases per million globally [1,2]. However, its incidence rate has been increasing since the 1950s [3,4]. MG is an acquired disease in which autoantibodies attack a patient's own acetylcholine receptors (AchRs). The trigger factors for developing these autoantibodies are yet to be clearly identified. Among all the factors, some infections have been thought to play a major role in causing autoimmune diseases. However, no specific pathogen strongly linked to MG has been reported in the literature. Knowing what microorganism infection would raise the risk of developing MG allows us to manage it more aggressively in order to avoid a rare but devastating consequence.

Mycoplasma pneumoniae (M. pneumoniae) is one of the most common pathogenic bacteria of upper respiratory tract infection, acute bronchitis, and community-acquired pneumonia (CAP) worldwide. In Asia, 8-23\% of the incidence of CAP is attributed to M. pneumoniae infection, which is the second most common bacterial pathogen and only falls behind Streptococcus pneumoniae [5]. Apart from respiratory symptoms, more importantly, $M$. pneumoniae infections are also associated with variable extrapulmonary manifestation, including neurological, cardiac, hematological, dermatological, and gastrointestinal symptoms. This phenomenon is quite unusual among other bacterial infections; however, the underlying pathophysiology remains controversial. One of the most common hypothesis is autoimmunity [6-8]. Many autoimmune diseases have been reported to follow M. pneumoniae infections, such as autoimmune hemolytic anemia, Guillain-Barre syndrome, and acute disseminated encephalomyelitis, etc. [9-11]. Recent studies have suggested that the excessive expression of T helper 17 cells (Th17) and associated cytokines, e.g., IL-17, could be one of the possible pathogenesis [12].

Alternatively, studies aimed at determining the pathogenesis of MG have revealed some connections between MG and Th17/Treg imbalance [13,14]. Figure 1 shows our working hypothesis. Although sharing those overlapping pathways in Th17 and IL 17 cascades, no previous studies have evaluated the epidemiological relationship between $M$. pneumoniae infection and subsequent development of MG. Few case reports have directly linked M. pneumoniae infection to subsequent MG development but no study with larger scale were carried out. Therefore, we conducted a nationwide matched cohort study to investigate whether M. pneumoniae infection would be associated with an increased risk of subsequent development of MG.

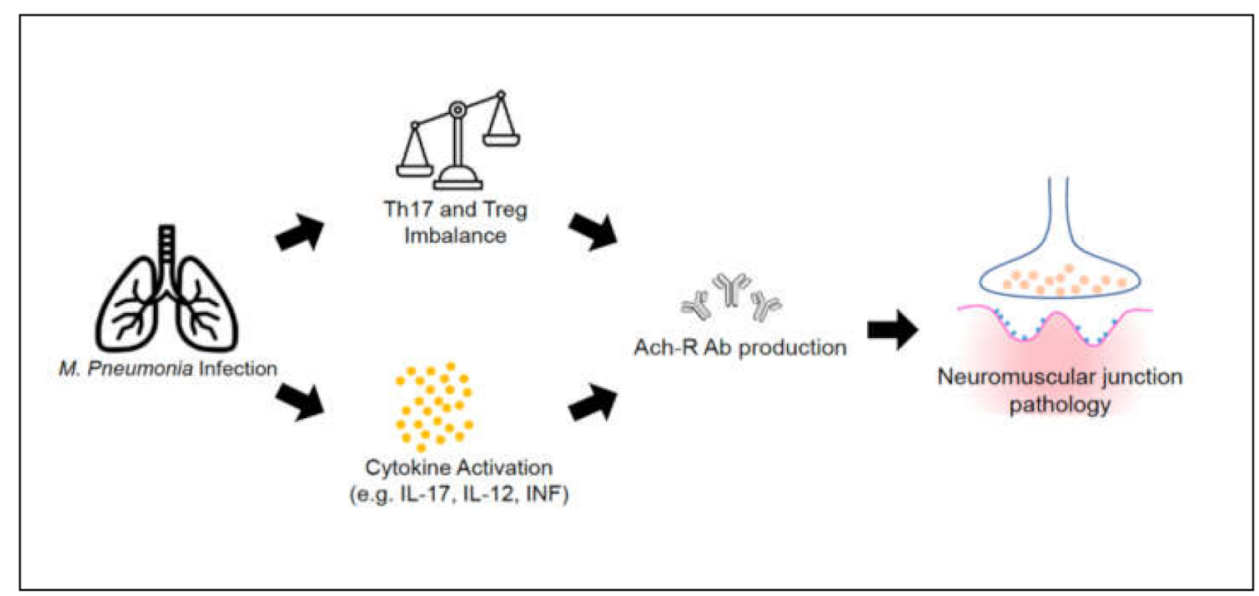

Figure 1. The hypothesis of the cohort study for M. pneumoniae infection and MG development.

\section{Materials and Methods}

\subsection{Data Source}

The study used data from the inpatient datasets of the National Health Insurance Research Database (NHIRD). The NHIRD was established by the National Health Insurance program of Taiwan launched in 1995. Encryption and anonymity were performed to protect the privacy of beneficiaries. The claims data contain information regarding the 
basic demographics; disease diagnosis coding based on the International Classification of Diseases, 9th Revision, Clinical Modification (ICD-9-CM); and details of inpatient orders, inpatient admission, and discharge dates. The study was approved by the Research Ethics Committee at China Medical University and Hospital (CMUH-104-REC2-115(CR-6)).

\subsection{Study Population and Main Outcome}

The study population was randomly sampled by BNHI from the original claim data of NHIRD. There was no significant difference in the gender $(p=0.613)$ [15] and age distribution [16] between the patients in the randomly sampled data and the original NHIRD.

In Taiwan, the diagnosis of M. pneumoniae is based on a positive serologic test result [17], including the measurement of specific IgM in a blood sample, or a four-fold or greater increase or decrease in the value of a specific IgG. Suspected cases of infection are further confirmed by clinical examination or imaging [18]. Because of the strict review mechanism for antibiotic use [19], consensus must be reached among infectious physicians, chest physicians, and specialty-trained coders for all M. pneumoniae diagnoses. By adopting such well-established diagnostic criteria, doctors in Taiwan do their best to minimize misclassification.

The date of the initial diagnosis of M. pneumoniae infection (ICD-9-CM 483.0) was defined as the index date, and the end of follow-up was the date of diagnosis of MG (ICD9-CM 358.0), the date of withdrawal or death, or 31 December 2013, whichever came first. The diagnosis of MG was validated with at least one admission or at least two consistent OPD visits examined by neurologists.

Subjects with missing registry claim data, such as unknown sex, inconsistent birth date, or incomplete insurance data, were excluded. Other exclusion criteria were as follows: the index year not between 2000 and 2012; MG diagnosed before the index date; age < 18 years; and follow-up duration less than 0 . Subjects with M. pneumoniae infection were included in the M. pneumoniae cohort, whereas those who were never infected with M. pneumoniae were included in the non-M. pneumoniae cohort; $M$. pneumoniae patients were matched with non-M. pneumoniae patients at a 1:4 ratio by propensity score matching on 5-year age group, sex, index year, and baseline comorbidities. We followed inpatients with a diagnosis of $M$. pneumoniae who were discharged from the hospital for three outcomes: diagnosis of MG, termination of health insurance coverage, or end of the study (31 December 2013).

\subsection{Control Population}

Hospital control cohort was selected from among patients without a diagnosis of $M$. pneumoniae infection in the same database. For each patient with M. pneumoniae infection, we randomly selected four controls using the incidence density sampling method and matched them by 5 -year age group, sex, and index year. We calculated the propensity score for admission to hospital with M. pneumoniae infection in the control cohort matched by age, sex, and relevant comorbidities. We defined propensity score as the probability of admission to hospital for MG conditional on baseline covariates derived by the logistic regression model (Table 1). We performed a 1:4 propensity score matching (PSM) using the greedy matching algorithm to ensure a matched pair with similar distribution of relevant comorbidities at baseline. The groups were by nearest-neighbor PSM, initially to the 8th digit and then to the first digit; that is, matching was initially done in a caliper width of 0.0000001 , which was then increased for unmatched cases to 0.1 . We reconsidered the matching criteria and performed a rematch (using the greedy matching algorithm). For each individual in the M. pneumoniae cohort, the corresponding comparisons were selected based on the nearest propensity score. 
Table 1. The baseline characteristic and comorbidities of patients with and without Mycoplasma pneumoniae (M. pneumoniae) infection in cohort study.

\begin{tabular}{|c|c|c|c|c|c|c|}
\hline \multirow[b]{3}{*}{ Variables } & \multicolumn{6}{|c|}{ Mycoplasma pneumoniae Infection } \\
\hline & \multicolumn{2}{|c|}{ No $(N=9712)$} & \multicolumn{2}{|c|}{ Yes $(N=2428)$} & \multirow[b]{2}{*}{$p$-Value } & \multirow[b]{2}{*}{ SMD } \\
\hline & $n$ & $\%$ & $n$ & $\%$ & & \\
\hline Gender & & & & & 0.013 & 0.057 \\
\hline Female & 5895 & $60.7 \%$ & 1406 & $57.9 \%$ & & \\
\hline Male & 3817 & $39.3 \%$ & 1022 & $42.1 \%$ & & \\
\hline \multicolumn{7}{|l|}{ Age, year } \\
\hline $20-40$ & 3856 & $39.7 \%$ & 1035 & $42.6 \%$ & 0.007 & 0.059 \\
\hline $40-60$ & 3188 & $32.8 \%$ & 794 & $32.7 \%$ & & 0.003 \\
\hline$\geq 60$ & 2668 & $27.5 \%$ & 599 & $24.7 \%$ & & 0.064 \\
\hline mean, (SD) & 48.7 & $(18.3)$ & 47.5 & $(18.1)$ & 0.002 & 0.069 \\
\hline \multicolumn{7}{|l|}{ Comorbidities } \\
\hline Hypertension & 1744 & $18.0 \%$ & 403 & $16.6 \%$ & 0.124 & 0.036 \\
\hline Diabetes mellitus & 3231 & $33.3 \%$ & 739 & $30.4 \%$ & 0.008 & 0.061 \\
\hline -Hyperlipidemia & 0 & $0.0 \%$ & 0 & $0.0 \%$ & & \\
\hline Coronary artery disease & 292 & $3.0 \%$ & 86 & $3.5 \%$ & 0.196 & 0.030 \\
\hline CKD & 455 & $4.7 \%$ & 102 & $4.2 \%$ & 0.334 & 0.023 \\
\hline Chronic liver diseases & 2428 & $25.0 \%$ & 614 & $25.3 \%$ & 0.789 & 0.007 \\
\hline $\begin{array}{c}\text { Cerebrovascular } \\
\text { accident }\end{array}$ & 1401 & $14.4 \%$ & 322 & $13.3 \%$ & 0.151 & 0.034 \\
\hline COPD & 3833 & $39.5 \%$ & 943 & $38.8 \%$ & 0.587 & 0.013 \\
\hline Hashimoto thyroiditis & 40 & $0.4 \%$ & 11 & $0.5 \%$ & 0.916 & 0.006 \\
\hline Graves' disease & 212 & $2.2 \%$ & 28 & $1.2 \%$ & 0.001 & 0.080 \\
\hline SLE & 48 & $0.5 \%$ & 20 & $0.8 \%$ & 0.073 & 0.041 \\
\hline Rheumatoid arthritis & 19 & $0.2 \%$ & 11 & $0.5 \%$ & 0.040 & 0.045 \\
\hline Malignancies & 833 & $8.6 \%$ & 160 & $6.6 \%$ & 0.002 & 0.075 \\
\hline
\end{tabular}

CKD: chronic kidney disease; COPD: chronic obstructive pulmonary disease; SLE: systemic lupus erythematosus. SMD: standard mean difference ( $<0.1$ means no difference between two group).

\subsection{Covariates and Comorbidities}

The baseline comorbidities included hypertension (ICD-9-CM: 401-405), diabetes (ICD-9-CM: 250), hyperlipidemia (ICD-9-CM: 272), coronary artery disease (ICD-9-CM: 410-414), chronic kidney disease (CKD) (ICD-9-CM: 585), chronic liver diseases (ICD-9-CM: 571), cerebrovascular accident (ICD-9-CM: 430-438), chronic obstructive pulmonary disease (COPD) (ICD-9-CM: 490-496), Hashimoto thyroiditis (ICD-9-CM: 245.2), Graves' disease (ICD-9-CM: 242.0), systemic lupus erythematosus (SLE, ICD-9-CM: 710.0), rheumatoid arthritis (ICD-9-CM: 714.0), and malignancies (ICD-9-CM: 140-208). All comorbidities were recorded and traced back 2 years before the index date.

\subsection{Statistical Analysis}

To account for the difference of demographic variables and comorbidities between control and study groups, we performed a propensity score matching. We also included the covariates into the multivariable model for the adjustment.

Demographic differences between the M. pneumoniae and control patients were examined using independent $t$-tests for continuous variables and chi-square tests for categorial variables. We also calculated the standard mean difference for the measurement of effect size. The incidence rate was calculated by dividing the number of events by sum of the person-year in the follow-up period. To examine the independent association of M. pneumoniae with MG, a Cox proportional hazard regression analysis was conducted to estimate the hazard ratio (HR), and 95\% confidence interval (CI). Variables that were statistically significant in the univariable model were further examined in the multivariable model. If no variables were found to be significant in the univariable model, then no further multivariable analysis was conducted. Covariates comprised age, sex, and baseline 
comorbidities listed in Table 1. Statistical significance was defined at $p$-value $<0.05$. Data analyses and plotting were performed using SAS 9.4 (SAS Institute Inc., Cary, NC, USA).

\subsection{Sensitivity Analysis}

Because of the risk of potential source of bias and underestimating the number of MG recorded, sensitivity analysis was performed by a case control study design, comprising 515 patients with MG diagnosed and coded by neurologists, was conducted between 2006 and 2013. This sensitivity analysis was designed to test whether a history of M. pneumoniae infection is associated with new onset of MG. The history of M. pneumoniae infection was identified via physicians' primary diagnosis from inpatients database before the diagnosis of MG within 24 months.

\section{Results}

The population consisted of 12,140 subjects; $2428(20 \%)$ subjects were given the diagnosis of M. pneumoniae infection by a health care provider and $9712(80 \%)$ subjects were not.

Table 1 shows the characteristics of patients with and without M. pneumoniae infection in this study. M. pneumoniae infection was more prevalent in the $20-40$ age group, $43 \%$, and females, 58\%. DM, Grave's disease, RA, and malignancies were less prevalent in the M. pneumoniae infection group. No significant differences were found in the other comorbidities between the groups.

Table 2 shows the findings of Cox regression analyses of each risk factor associated with MG among subjects. The incidence rates of MG in the non-M. pneumoniae and $M$. pneumoniae cohorts were 0.96 and 1.97 per 10,000 person-years, respectively. No significant difference was noted in the MG risk between the cohorts ( $\mathrm{HR}=2.14,95 \% \mathrm{CI}=[0.39,11.72]$ ). Similarly, no significance was found among the other covariates listed in Table 1, including hypertension $(\mathrm{HR}=0.98,95 \% \mathrm{CI}=[0.11,8.44])$, diabetes mellitus $(\mathrm{HR}=1.12,95 \%$ $\mathrm{CI}=[0.2,6.11])$, hyperlipidemia, coronary artery disease, chronic kidney disease $(\mathrm{HR}=1.59$, $95 \% \mathrm{CI}=[0.27,7.97])$, cerebrovascular accident $(\mathrm{HR}=4.09,95 \% \mathrm{CI}=[0.74,22.57])$, COPD $(\mathrm{HR}=1.57,95 \% \mathrm{CI}=[0.32,7.78])$, Hashimoto thyroiditis, Graves' disease $(\mathrm{HR}=5.36,95 \%$ $\mathrm{CI}=[0.59,48.97]), \mathrm{SLE}$, rheumatoid arthritis, and malignancies.

Table 2. Incidence rate and hazard ratio of myasthenia gravis (MG).

\begin{tabular}{|c|c|c|c|c|c|}
\hline \multirow[b]{2}{*}{ Variables } & \multicolumn{5}{|c|}{ Myasthenia Gravis } \\
\hline & $n$ & PY & IR & Crude HR & $(95 \% \mathrm{CI})$ \\
\hline \multicolumn{6}{|c|}{$\begin{array}{l}\text { M. pneumoniae } \\
\text { infection }\end{array}$} \\
\hline No & 4 & 41,484 & 0.96 & 1.00 & (reference) \\
\hline Yes & 2 & 10,133 & 1.97 & 2.14 & $(0.39,11.72)$ \\
\hline \multicolumn{6}{|l|}{ Gender } \\
\hline Female & 4 & 31,485 & 1.27 & 1.00 & (reference) \\
\hline Male & 2 & 20,132 & 0.99 & 0.81 & $(0.15,4.43)$ \\
\hline \multicolumn{6}{|l|}{ Age, year } \\
\hline $20-40$ & 1 & 21,977 & 0.46 & 1.00 & (reference) \\
\hline $40-60$ & 3 & 17,349 & 1.73 & 3.74 & $(0.39,35.96)$ \\
\hline$\geq 60$ & 2 & 12,292 & 1.63 & 3.51 & $(0.32,38.72)$ \\
\hline \multicolumn{6}{|c|}{ Comorbidities } \\
\hline \multicolumn{6}{|c|}{ Hypertension } \\
\hline No & 5 & 43,096 & 1.16 & 1.00 & (reference) \\
\hline Yes & 1 & 8521 & 1.17 & 0.98 & $(0.11,8.44)$ \\
\hline \multicolumn{6}{|c|}{ Diabetes mellitus } \\
\hline No & 4 & 35,588 & 1.12 & 1.00 & (reference) \\
\hline Yes & 2 & 16,029 & 1.25 & 1.12 & $(0.2,6.11)$ \\
\hline
\end{tabular}


Table 2. Cont.

\begin{tabular}{|c|c|c|c|c|c|}
\hline \multirow[b]{2}{*}{ Variables } & \multicolumn{5}{|c|}{ Myasthenia Gravis } \\
\hline & $n$ & PY & IR & Crude HR & $(95 \% \mathrm{CI})$ \\
\hline \multicolumn{6}{|c|}{ Hyperlipidemia } \\
\hline No & 6 & 50,303 & 1.19 & & \\
\hline Yes & 0 & 1315 & 0.00 & & \\
\hline \multicolumn{6}{|c|}{$\begin{array}{c}\text { Coronary artery } \\
\text { disease }\end{array}$} \\
\hline No & 6 & 49,479 & 1.21 & & \\
\hline Yes & 0 & 2138 & 0.00 & & \\
\hline \multicolumn{6}{|l|}{ CKD } \\
\hline No & 4 & 39,046 & 1.02 & 1.00 & (reference) \\
\hline Yes & 2 & 12,571 & 1.59 & 1.45 & $(0.27,7.97)$ \\
\hline \multicolumn{6}{|c|}{$\begin{array}{c}\text { Cerebrovascular } \\
\text { accident }\end{array}$} \\
\hline No & 4 & 45,549 & 0.88 & 1.00 & (reference) \\
\hline Yes & 2 & 6069 & 3.30 & 4.09 & $(0.74,22.57)$ \\
\hline \multicolumn{6}{|l|}{ COPD } \\
\hline No & 3 & 31,924 & 0.94 & 1.00 & (reference) \\
\hline Yes & 3 & 19,694 & 1.52 & 1.57 & $(0.32,7.78)$ \\
\hline \multicolumn{6}{|c|}{ Hashimoto thyroiditis } \\
\hline No & 6 & 51,429 & 1.17 & & \\
\hline Yes & 0 & 188 & 0.00 & & \\
\hline \multicolumn{6}{|c|}{ Graves' disease } \\
\hline No & 5 & 50,138 & 1.00 & 1.00 & (reference) \\
\hline Yes & 1 & 1479 & 6.76 & 5.36 & $(0.59,48.97)$ \\
\hline \multicolumn{6}{|l|}{ SLE } \\
\hline No & 6 & 51,384 & 1.17 & & \\
\hline Yes & 0 & 233 & 0.00 & & \\
\hline \multicolumn{6}{|c|}{ Rheumatoid arthritis } \\
\hline $\mathrm{No}$ & 6 & 51,504 & 1.16 & & \\
\hline Yes & 0 & 113 & 0.00 & & \\
\hline \multicolumn{6}{|c|}{ Malignancies } \\
\hline No & 6 & 47,644 & 1.26 & & \\
\hline Yes & 0 & 3973 & 0.00 & & \\
\hline
\end{tabular}

CKD: chronic kidney disease; COPD: chronic obstructive pulmonary disease; SLE: systemic lupus erythematosus PY: person-year; IR: incidence rate per 10,000 person-year; HR: hazard ratio; CI: confidence interval.

To confirm our finding, we conducted a case-control model sensitivity analysis using the same database for cross-validation. As shown in Table 3, the odds ratio for subsequent development of MG in M. pneumoniae-infected patients was found to be 0.67 $(95 \% \mathrm{CI}=[0.08,5.50])$. No significant association between $M$. pneumoniae infection and MG was noted in the sensitivity analysis.

Table 3. Sensitivity analysis with case control study design.

\begin{tabular}{|c|c|c|c|c|c|c|c|}
\hline \multirow[b]{3}{*}{ Variables } & \multicolumn{7}{|c|}{ Myasthenia Gravis } \\
\hline & \multicolumn{2}{|c|}{$\begin{array}{c}\text { No } \\
(N=2060)\end{array}$} & \multicolumn{2}{|c|}{$\begin{array}{c}\text { Yes } \\
(N=515)\end{array}$} & \multirow[b]{2}{*}{ OR } & \multirow[b]{2}{*}{$(95 \% \mathrm{CI})$} & \multirow[b]{2}{*}{$p$-Value } \\
\hline & $n$ & $\%$ & $n$ & $\%$ & & & \\
\hline \multicolumn{8}{|c|}{$\begin{array}{l}\text { M. pneumoniae } \\
\text { infection }\end{array}$} \\
\hline No & 2054 & $99.7 \%$ & 514 & $99.8 \%$ & 1.00 & (reference) & \\
\hline Yes & 6 & $0.3 \%$ & 1 & $0.2 \%$ & 0.67 & $(0.08,5.50)$ & 0.707 \\
\hline \multicolumn{8}{|l|}{ Gender } \\
\hline Female & 1163 & $56 \%$ & 290 & $56 \%$ & 1.00 & (reference) & \\
\hline Male & 897 & $44 \%$ & 225 & $44 \%$ & 1.01 & $(0.83,1.22)$ & 0.952 \\
\hline
\end{tabular}


Table 3. Cont.

\begin{tabular}{|c|c|c|c|c|c|c|c|}
\hline \multirow[b]{3}{*}{ Variables } & \multicolumn{7}{|c|}{ Myasthenia Gravis } \\
\hline & \multicolumn{2}{|c|}{$\begin{array}{c}\text { No } \\
(N=2060)\end{array}$} & \multicolumn{2}{|c|}{$\begin{array}{c}\text { Yes } \\
(N=515)\end{array}$} & \multirow[b]{2}{*}{ OR } & \multirow[b]{2}{*}{$(95 \% \mathrm{CI})$} & \multirow[b]{2}{*}{$p$-Value } \\
\hline & $n$ & $\%$ & $n$ & $\%$ & & & \\
\hline \multicolumn{8}{|l|}{ Age, year } \\
\hline $20-40$ & 469 & $23 \%$ & 116 & $23 \%$ & 1.00 & (reference) & \\
\hline $40-60$ & 861 & $42 \%$ & 236 & $46 \%$ & 1.11 & $(0.86,1.42)$ & 0.419 \\
\hline$\geq 60$ & 730 & $35 \%$ & 163 & $32 \%$ & 0.90 & $(0.69,1.18)$ & 0.449 \\
\hline mean, (SD) & 54.4 & $(18.4)$ & 52.5 & $(16.0)$ & 0.99 & $(0.99,1.00)$ & 0.035 * \\
\hline \multicolumn{8}{|l|}{ Comorbidities } \\
\hline Hypertension & 829 & $40 \%$ & 199 & $39 \%$ & 0.94 & $(0.77,1.14)$ & 0.507 \\
\hline $\begin{array}{l}\text { Diabetes } \\
\text { mellitus }\end{array}$ & 462 & $22 \%$ & 105 & $20 \%$ & 0.89 & $(0.70,1.12)$ & 0.318 \\
\hline Hyperlipidemia & 738 & $36 \%$ & 187 & $36 \%$ & 1.02 & $(0.84,1.25)$ & 0.837 \\
\hline CAD & 99 & $5 \%$ & 17 & $3 \%$ & 0.68 & $(0.40,1.14)$ & 0.143 \\
\hline CKD & 97 & $5 \%$ & 12 & $2 \%$ & 0.48 & $(0.26,0.89)$ & 0.019 * \\
\hline $\begin{array}{c}\text { Chronic liver } \\
\text { diseases }\end{array}$ & 586 & $28 \%$ & 143 & $28 \%$ & 0.97 & $(0.78,1.20)$ & 0.759 \\
\hline CVA & 379 & $18 \%$ & 98 & $19 \%$ & 1.04 & $(0.82,1.33)$ & 0.742 \\
\hline COPD & 718 & $35 \%$ & 142 & $28 \%$ & 0.71 & $(0.58,0.88)$ & $0.002^{* *}$ \\
\hline $\begin{array}{l}\text { Hashimoto } \\
\text { thyroiditis }\end{array}$ & 18 & $1 \%$ & 5 & $1 \%$ & 1.11 & $(0.41,3.01)$ & 0.834 \\
\hline Graves' disease & 76 & $4 \%$ & 20 & $4 \%$ & 1.05 & $(0.64,1.74)$ & 0.835 \\
\hline SLE & 28 & $1 \%$ & 7 & $1 \%$ & 1.00 & $(0.43,2.30)$ & $<0.99$ \\
\hline RA & 9 & $0.44 \%$ & 2 & $0.39 \%$ & 0.89 & $(0.19,4.12)$ & 0.880 \\
\hline Malignancies & 253 & $12 \%$ & 56 & $11 \%$ & 0.87 & $(0.64,1.18)$ & 0.380 \\
\hline
\end{tabular}

CAD: coronary artery disease; CKD: chronic kidney disease; CVA: cerebrovascular accident; COPD: chronic obstructive pulmonary disease; SLE: systemic lupus erythematosus; RA: rheumatoid arthritis; OR: odds ratio; CI: confidence interval; ${ }^{*}: p$-value $<0.5 ;{ }^{* *}: p$-value $<0.01$.

\section{Discussion}

To the best of our knowledge, the present study is the first population-based nationwide study to use a longitudinal dataset (NHIRD) in order to assess the relationship between M. pneumoniae infection and the risk of developing MG. Our results demonstrated the lack of association between $M$. pneumoniae infection and the subsequent development of MG. A cross-validation analysis performed using a case-control method also revealed the same finding.

M. pneumoniae is the second most bacterial pathogen for CAP not only in Taiwan but also in most of the other countries worldwide [20,21]. In the US, it accounts for approximately $2-12 \%$ of adult cases and approximately $7.5 \%$ of children cases admitted for CAP [22]. In Taiwan, up to $14 \%$ of hospitalized CAP patients are attributed to $M$. pneumoniae [23], making it a major healthcare burden. However, this fact is often overlooked because of its mild symptoms.

Besides respiratory symptoms, $M$. pneumoniae infection also causes extra-pulmonary complications across multiple systems such as neurological, musculoskeletal, dermatologi$\mathrm{cal}$, etc. Some autoimmune diseases were also thought to be associated with M. pneumoniae infection, including rheumatoid arthritis (RA) [24], acute inflammatory demyelinating polyneuropathy (AIDP) [10], adult still disease [25], cold agglutinin hemolysis [9], and so forth.

The neurological complications of M. pneumoniae infection include meningoencephalitis, acute disseminated encephalomyelitis (ADEM), Guillain-Barre syndrome (GBS), and polyneuropathy, which are well documented in the literature. Autoimmunity is also one of the most prevalent theories, along with neurotoxin and direct invasion [26-28]. Some species in the Mycoplasma genus could produce neurotoxins. Nevertheless, currently, there is no evidence that $M$. pneumoniae could produce neurotoxins inside the human body. 
Direct invasion was reported in some CNS complications by direct culture. However, it would be less likely because MG is a neuromuscular junction disease.

A previous study on an animal model reported that the antigens of M. pneumoniae could induce potent immune reaction and enhanced Th17 cell and IL-17 response both in vivo and in vitro [29]. The investigators repeatedly inoculated specific-pathogen-free mice with M. pneumoniae intranasally. The result demonstrated that the M. pneumoniae antigen would stimulate the proliferation of mouse lymphocytes and cause the production of IL-17A and IL-10, thereby inducing a Th17 dominant immune reaction. The severity of disease is correlated with higher doses or more frequent inoculation.

In their study, Wang et al. included 30 children with M. pneumoniae pneumonia and 21 healthy controls to compare the frequency of Th17 cells [30]. They used flow cytometry to analyze Th17 cells in the peripheral blood in both groups. The results demonstrated that the percentage of Th17 cells increased in patients with M. pneumoniae infection. Subgroup analysis also revealed that the expression of Th17 cells was higher in patients with extrapulmonary manifestation than in those who did not have extrapulmonary presentation.

Guo et al. further analyzed the relationship between Th17 and Treg in M. pneumoniae infection [12] and found that the Th17/Treg ratio is significantly higher in $M$. pneumoniae-infected patients than in healthy controls. However, they did not address the extrapulmonary symptoms.

The Th17 and IL-17 cascades have also been proven to take part in developing autoimmune diseases [31]. Studies have found that IL-23, IL-17, Th17, and Treg cell pathways play important roles in chronic inflammation in the thymuses of MG patients [32,33]. Wang et al. reported that in MG patients with thymomas, the levels of Th17 cells and their associated cytokines increase in the peripheral blood, while those of Treg cells decrease [14]. Similar conditions did not exist in patients with a normal thymus or thymic hyperplasia in their study. However, they also found that the frequency of Th17 cells correlates with the concentration of AChR antibodies in all MG patients included.

To our knowledge, there has been two case report on ocular MG following M. pneumoniae infection [34,35]. Yiş et al. described a 3-year-old boy who presented with 10 days of sore throat and 3 days of bilateral ptosis. MG was diagnosed with negative MRI finding and positive neostigmine and ice pack test. M. pneumoniae infection was confirmed via serial serology tests. Aydin et al. also presented a 6-year-old girl with fever, nasal flow and obstruction, fatigue, and sudden onset of left eyelid ptosis developed 3 days after prior symptoms. M. pneumoniae infection was diagnosed by both serology and respiratory swab PCR. MG was diagnosed by empirical pyridostigmine bromide and the detect of Acetylcholine receptor antibody since the patient cannot cooperate on EMG.

Another study conducted by Iwasa et al. in Japan reported that variations in the anti-acetylcholine receptor antibody (AChR-Ab) titer in MG are significantly associated with the incidence rate of M. pneumoniae infection using time-series analysis with data from a single hospital in 6 years of follow-up period. They prospectively collected AChR-Ab from MG patients regularly and correlated it with data from 29 monitoring hospitals. Their findings showed that the seasonal change of $\mathrm{AChR}-\mathrm{Ab}$ titer was significantly correlated with the epidemic patterns of $M$. pneumoniae infections, suggesting that M. pneumoniae may provoke an immune reaction in the host with or without symptoms [36].

Our study cohort is representative of and can be generalized to the general population of Taiwan. However, despite all the possible associations mentioned above, our result described an HR of 2.14 in patients with M. pneumoniae infection, without reaching statistically significance.

There are several limitations to our study that should be mentioned. First, in our data extracted from the NHIRD, the cases were identified purely by ICD-9-CM codes. No diagnostic and demographic data, such as family history, lifestyle, BMI, and medication use, could be retrieved. Laboratory reports including immunological data cannot be provided in the NHIRD and this is an inherent limitation in the study. Second, the number of MG patients included in the study was small. Given that MG is not a common disease 
and our study was conducted within a limited population, we tried to establish a cohort that resembles the real-world condition. Finally, the diagnosis of M. pneumoniae infection in Taiwan mostly relies on serology tests, which are reported to not be as sensitive as polymerase chain reaction [37]. However, because that the accessibility and affordability of the healthcare system in Taiwan is outstanding as opposed to those of most countries and the diagnosing protocol is relatively well established, we still consider our findings to be representative of the real-world conditions. Further studies with larger population and more MG cases are warranted to confirm our findings.

\section{Conclusions}

Although sharing immunological activation pathways at cellular levels and with similar seasonal trends, the present study found that $M$. pneumoniae infection was not associated with subsequent development of MG in Taiwan. However, it is a step forward. Since this observation study was performed in one relatively small country, if similar studies were to be done in the future in other countries of non-Asian origin, the results may be different.

Author Contributions: R.C. and M.-C.C.; methodology, R.C.; acquisition of data, H.-T.Y.; formal analysis and interpretation of data, H.-T.Y.; writing — original draft preparation, K.C.; writing — review and editing, R.C., J.C.-C.W. and M.-C.C.; supervision, J.C.-C.W.; project administration, J.C.-C.W. All authors have read and agreed to the published version of the manuscript.

Funding: This research received no external funding.

Institutional Review Board Statement: The study was approved by the Research Ethics Committee at China Medical University and Hospital (CMUH-104-REC2-115(CR-6)).

Informed Consent Statement: Patients' consent was waived due to the linked identity data were removed and patients' data could not be identified.

Data Availability Statement: The data presented in this study are available on request from the corresponding author.

Conflicts of Interest: The authors declare no conflict of interest.

\section{References}

1. Carr, A.S.; Cardwell, C.R.; McCarron, P.O.; McConville, J. A systematic review of population based epidemiological studies in Myasthenia Gravis. BMC Neurol. 2010, 10, 46. [CrossRef] [PubMed]

2. Heldal, A.T.; Eide, G.E.; Gilhus, N.E.; Romi, F. Geographical distribution of a seropositive myasthenia gravis population. Muscle Nerve 2012, 45, 815-819. [CrossRef] [PubMed]

3. Grob, D.; Brunner, N.; Namba, T.; Pagala, M. Lifetime course of myasthenia gravis. Muscle Nerve 2008, 37, 141-149. [CrossRef] [PubMed]

4. Phillips, L.H. The epidemiology of myasthenia gravis. Semin. Neurol. 2004, 24, 17-20. [CrossRef]

5. Peto, L.; Nadjm, B.; Horby, P.; Ngan, T.T.; van Doorn, R.; Van Kinh, N.; Wertheim, H.F. The bacterial aetiology of adult community-acquired pneumonia in Asia: A systematic review. Trans. R. Soc. Trop. Med. Hyg. 2014, 108, 326-337. [CrossRef]

6. Narita, M. Pathogenesis of neurologic manifestations of Mycoplasma pneumoniae infection. Pediatric Neurol. 2009, 41, 159-166. [CrossRef]

7. Saraya, T.; Kurai, D.; Nakagaki, K.; Sasaki, Y.; Niwa, S.; Tsukagoshi, H.; Nunokawa, H.; Ohkuma, K.; Tsujimoto, N.; Hirao, S.; et al. Novel aspects on the pathogenesis of Mycoplasma pneumoniae pneumonia and therapeutic implications. Front. Microbiol. 2014, 5, 410. [CrossRef]

8. Waites, K.B.; Xiao, L.; Liu, Y.; Balish, M.F.; Atkinson, T.P. Mycoplasma pneumoniae from the Respiratory Tract and Beyond. Clin. Microbiol. Rev. 2017, 30, 747-809. [CrossRef]

9. Khan, F.Y. Mycoplasma pneumoniae associated with severe autoimmune hemolytic anemia: Case report and literature review. Braz. J. Infect. Dis. 2009, 13, 77-79. [CrossRef]

10. Meyer Sauteur, P.M.; Huizinga, R.; Tio-Gillen, A.P.; Roodbol, J.; Hoogenboezem, T.; Jacobs, E.; van Rijn, M.; van der Eijk, A.A.; Vink, C.; de Wit, M.C.; et al. Mycoplasma pneumoniae triggering the Guillain-Barré syndrome: A case-control study. Ann. Neurol. 2016, 80, 566-580. [CrossRef]

11. Riedel, K.; Kempf, V.A.; Bechtold, A.; Klimmer, M. Acute disseminated encephalomyelitis (ADEM) due to Mycoplasma pneumoniae infection in an adolescent. Infection 2001, 29, 240-242. [CrossRef] 
12. Guo, H.; He, Z.; Li, M.; Wang, T.; Zhang, L. Imbalance of peripheral blood Th17 and Treg responses in children with refractory Mycoplasma pneumoniae pneumonia. J. Infect. Chemother. 2016, 22, 162-166. [CrossRef]

13. Villegas, J.A.; Van Wassenhove, J.; Le Panse, R.; Berrih-Aknin, S.; Dragin, N. An imbalance between regulatory T cells and T helper 17 cells in acetylcholine receptor-positive myasthenia gravis patients. Ann. N. Y. Acad. Sci. 2018, 1413, 154-162. [CrossRef]

14. Wang, Z.; Wang, W.; Chen, Y.; Wei, D. T helper type 17 cells expand in patients with myasthenia-associated thymoma. Scand. J. Immunol. 2012, 76, 54-61. [CrossRef]

15. Longitudinal Health Insurance Database (LHID). Available online: https://nhird.nhri.org.tw/en/Data_Subsets.html (accessed on 7 July 2021).

16. Longitudinal Health Insurance Database (LHID). Available online: https://nhird.nhri.org.tw/date_cohort.html (accessed on 7 July 2021).

17. Bebear, C.M. Pathogenesis and laboratory diagnosis of Mycoplasma pneumoniae infections. Arch. Pediatrie 2008, 15, 1253-1256. [CrossRef]

18. Yeh, J.J.; Chen, S.C.; Chen, C.R.; Yeh, T.C.; Lin, H.K.; Hong, J.B.; Wu, B.T.; Wu, M.T. A high-resolution computed tomographybased scoring system to differentiate the most infectious active pulmonary tuberculosis from community-acquired pneumonia in elderly and non-elderly patients. Eur. Radiol. 2014, 24, 2372-2384. [CrossRef]

19. Tseng, S.H.; Lee, C.M.; Lin, T.Y.; Chang, S.C.; Chuang, Y.C.; Yen, M.Y.; Hwang, K.P.; Leu, H.S.; Yen, C.C.; Chang, F.Y. Combating antimicrobial resistance: Antimicrobial stewardship program in Taiwan. J. Microbiol. Immunol. Infect. 2012, 45, 79-89. [CrossRef]

20. Yen, M.Y.; Hu, B.S.; Chen, Y.S.; Lee, S.S.; Lin, Y.S.; Wann, S.R.; Tsai, H.C.; Lin, H.H.; Huang, C.K.; Liu, Y.C. A prospective etiologic study of community-acquired pneumonia in Taiwan. J. Formos. Med. Assoc. 2005, 104, 724-730.

21. Howard, L.S.; Sillis, M.; Pasteur, M.C.; Kamath, A.V.; Harrison, B.D. Microbiological profile of community-acquired pneumonia in adults over the last 20 years. J. Infect. 2005, 50, 107-113. [CrossRef]

22. Jain, S.; Self, W.H.; Wunderink, R.G.; Fakhran, S.; Balk, R.; Bramley, A.M.; Reed, C.; Grijalva, C.G.; Anderson, E.J.; Courtney, D.M.; et al. Community-Acquired Pneumonia Requiring Hospitalization among U.S. Adults. N. Engl. J. Med. 2015, 373, 415-427. [CrossRef]

23. Ma, Y.J.; Wang, S.M.; Cho, Y.H.; Shen, C.F.; Liu, C.C.; Chi, H.; Huang, Y.C.; Huang, L.M.; Huang, Y.C.; Lin, H.C.; et al. Clinical and epidemiological characteristics in children with community-acquired mycoplasma pneumonia in Taiwan: A nationwide surveillance. J. Microbiol. Immunol. Infect. 2015, 48, 632-638. [CrossRef] [PubMed]

24. Ramirez, A.S.; Rosas, A.; Hernandez-Beriain, J.A.; Orengo, J.C.; Saavedra, P.; de la Fe, C.; Fernandez, A.; Poveda, J.B. Relationship between rheumatoid arthritis and Mycoplasma pneumoniae: A case-control study. Rheumatology 2005, 44, 912-914. [CrossRef] [PubMed]

25. Perez, C.; Artola, V. Adult Still's Disease Associated with Mycoplasma pneumoniae Infection. Clin. Infect. Dis. 2001, 32, e105-e106. [CrossRef] [PubMed]

26. Biberfeld, G. Antibodies to brain and other tissues in cases of Mycoplasma pneumoniae infection. Clin. Exp. Immunol. 1971, 8 , 319-333.

27. Biberfeld, G.; Norberg, R. Circulating immune complexes in Mycoplasma pneumoniae infection. J. Immunol. 1974, 112, 413-415.

28. Komatsu, H.; Kuroki, S.; Shimizu, Y.; Takada, H.; Takeuchi, Y. Mycoplasma pneumoniae meningoencephalitis and cerebellitis with antiganglioside antibodies. Pediatric Neurol. 1998, 18, 160-164. [CrossRef]

29. Kurata, S.; Osaki, T.; Yonezawa, H.; Arae, K.; Taguchi, H.; Kamiya, S. Role of IL-17A and IL-10 in the antigen induced inflammation model by Mycoplasma pneumoniae. BMC Microbiol. 2014, 14, 156. [CrossRef]

30. Wang, X.; Chen, X.; Tang, H.; Zhu, J.; Zhou, S.; Xu, Z.; Liu, F.; Su, C. Increased Frequency of Th17 Cells in Children With Mycoplasma pneumoniae Pneumonia. J. Clin. Lab. Anal. 2016, 30, 1214-1219. [CrossRef]

31. Tabarkiewicz, J.; Pogoda, K.; Karczmarczyk, A.; Pozarowski, P.; Giannopoulos, K. The Role of IL-17 and Th17 Lymphocytes in Autoimmune Diseases. Arch. Immunol. Ther. Exp. 2015, 63, 435-449. [CrossRef]

32. Gradolatto, A.; Nazzal, D.; Truffault, F.; Bismuth, J.; Fadel, E.; Foti, M.; Berrih-Aknin, S. Both Treg cells and Tconv cells are defective in the Myasthenia gravis thymus: Roles of IL-17 and TNF- $\alpha$. J. Autoimmun. 2014, 52, 53-63. [CrossRef]

33. Villegas, J.A.; Bayer, A.C.; Ider, K.; Bismuth, J.; Truffault, F.; Roussin, R.; Santelmo, N.; Le Panse, R.; Berrih-Aknin, S.; Dragin, N. Il-23/Th17 cell pathway: A promising target to alleviate thymic inflammation maintenance in myasthenia gravis. J. Autoimmun. 2019, 98, 59-73. [CrossRef]

34. Yis, U.; Kurul, S.H.; Cakmakci, H.; Dirik, E. Mycoplasma pneumoniae: Nervous system complications in childhood and review of the literature. Eur. J. Pediatrics 2008, 167, 973-978. [CrossRef]

35. Aydın, Z.C.G.; Arslan, E.A. Neurological Complications of Mycoplasma pneumoniae Infection in Children. J. Pediatric Infect. 2019, 13, e67-e73. [CrossRef]

36. Iwasa, K.; Yoshikawa, H.; Hamaguchi, T.; Sakai, K.; Shinohara-Noguchi, M.; Samuraki, M.; Takahashi, K.; Yanase, D.; Ono, K.; Ishida, C.; et al. Time-series analysis: Variation of anti-acetylcholine receptor antibody titer in myasthenia gravis is related to incidence of Mycoplasma pneumoniae and influenza virus infections. Neurol. Res. 2018, 40, 102-109. [CrossRef]

37. Nilsson, A.C.; Björkman, P.; Persson, K. Polymerase chain reaction is superior to serology for the diagnosis of acute Mycoplasma pneumoniae infection and reveals a high rate of persistent infection. BMC Microbiol. 2008, 8, 93. [CrossRef] 